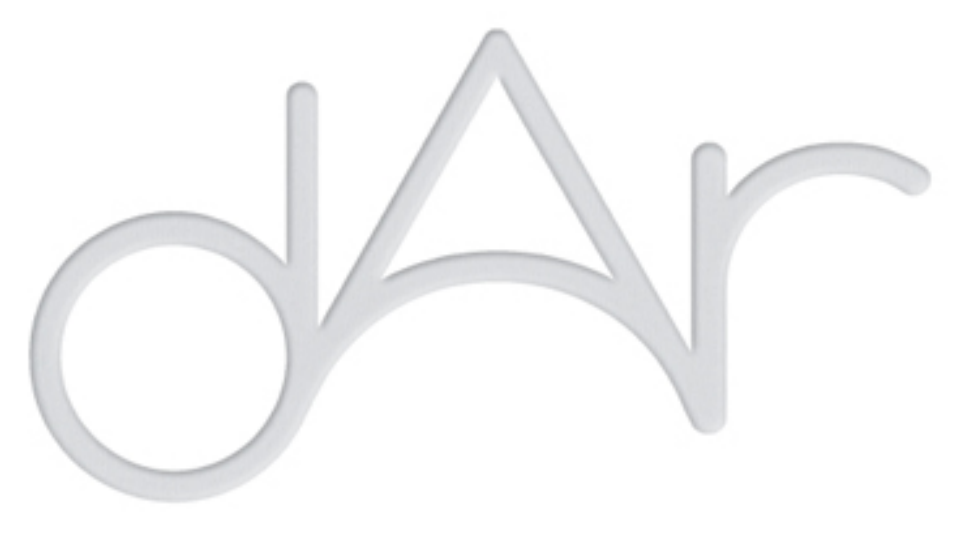

Corpos in e ex-situ: problemáticas da contextualização da imagem
Autor(es):
Bento, Maria José Travassos
Publicado por: Centro de Estudos em Arqueologia, Artes e Ciências do Património
URL persistente:
URI:http://hdl.handle.net/10316.2/39310
DOI:
DOI:http://dx.doi.org/10.14195/2182-844X_2_15

Accessed : $\quad$ 26-Apr-2023 12:26:52

A navegação consulta e descarregamento dos títulos inseridos nas Bibliotecas Digitais UC Digitalis, UC Pombalina e UC Impactum, pressupõem a aceitação plena e sem reservas dos Termos e Condições de Uso destas Bibliotecas Digitais, disponíveis em https://digitalis.uc.pt/pt-pt/termos.

Conforme exposto nos referidos Termos e Condições de Uso, o descarregamento de títulos de acesso restrito requer uma licença válida de autorização devendo o utilizador aceder ao(s) documento(s) a partir de um endereço de IP da instituição detentora da supramencionada licença.

Ao utilizador é apenas permitido o descarregamento para uso pessoal, pelo que o emprego do(s) título(s) descarregado(s) para outro fim, designadamente comercial, carece de autorização do respetivo autor ou editor da obra.

Na medida em que todas as obras da UC Digitalis se encontram protegidas pelo Código do Direito de Autor e Direitos Conexos e demais legislação aplicável, toda a cópia, parcial ou total, deste documento, nos casos em que é legalmente admitida, deverá conter ou fazer-se acompanhar por este aviso.

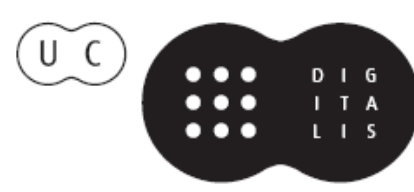




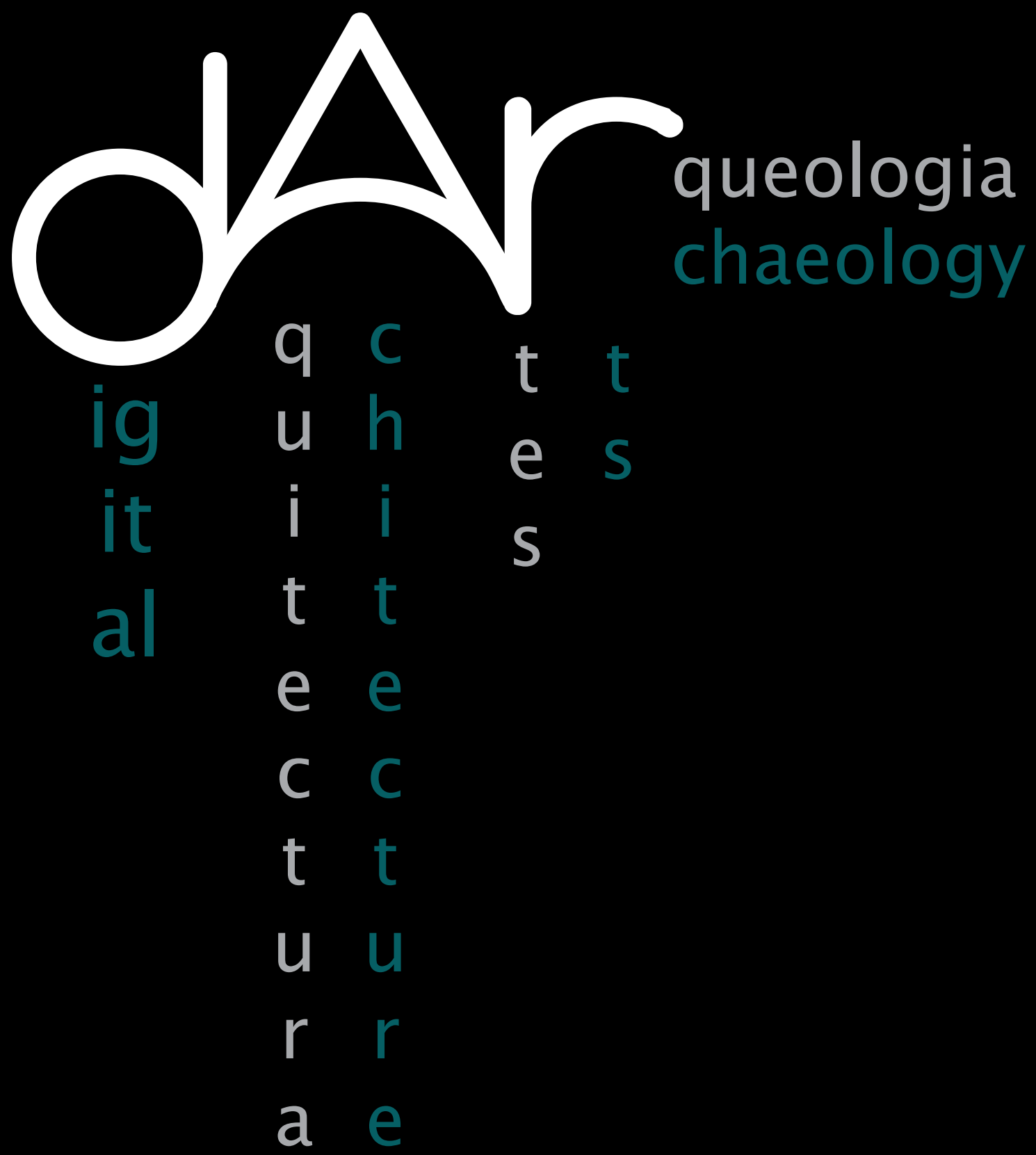




\section{CORPOS IN E EX-SITU: PROBLEMÁTICAS DA CONTEXTUALIZAÇÃO DA IMAGEM}

\section{Maria José Travassos Bento*}

CEAACP - Centro de Estudos em Arqueologia,

Artes e Ciências do Património

\section{RESUMO}

Apresenta-se um breve exercício de reflexão sobre até que ponto o contexto, per si, determina e conduz o observador na sua leitura da imagem de um corpo.

Este exercício baseia-se uma experiência que utiliza uma das imagens mais paradigmáticas do país, a fachada poente da nave manuelina do Convento de Cristo, a mesma que serve de suporte à emblemática Janela do Capítulo.

Decorrente de um conhecimento historiográfico e visual do objecto em análise, elencaram-se um conjunto de questões:

Se retirarmos do contexto todos os corpos do seu suporte qual é o resultado que obtemos?

Qual a leitura a fazer a cada um dos corpos, de forma individual?

Será que o isolamento do corpo altera a sua imagem e, consequentemente, a mensagem que lhe está subjacente?

Será que, quando isolados, nos é imediata a identificação desses corpos como pertencentes ao seu contexto original?

Será que aqueles corpos que nunca foram excluídos do seu contexto original, foram alguma vez percepcionados na sua totalidade individual?

E se o exercício consistir em inserir, virtualmente, esses mesmos corpos noutros contextos distintos? Será que a sua imagem ou a mensagem captada se altera?

Formalizou-se, ainda, um outro exercício:

Como apreenderemos um qualquer contexto sem os corpos?

Será o suporte refém dos elementos que o constituem?

Partindo destas questões, e exemplificando-as com recurso à manipulação de imagens, propõe-se uma reflexão sobre as problemáticas em questão, com o objectivo de mostrar o poder de mutação de um corpo quando alterado o seu contexto. No extremo, e num percurso que avoluma as interrogações, detectar-se-á um território de análise minado de conjecturas que podem interferir com linhas historiográficas montadas e com a inteligibilidade dos objectos e do tempo cultural e artístico em causa.

Palavras-chave: Corpo, imagem e contexto. 


\section{ABSTRACT}

It presents a brief exercise on the extent to which the context itself determines and conducts the observer on his reading of the image of a body. This exercise involves an experience that uses one of the most paradigmatic images of Portugal, the west facade of the Manueline nave of the Convent of Christ, the same one that supports the Chapter window. Arising from a historiographical and visual knowledge of the subject under review, a set of questions is proposed: If we remove the context from all bodies its support which is the result we get? What do you read from each of the bodies, on an individual basis? Does the isolation of the body changes its image and, consequently, the underlying message?

I wonder if, when isolated, us is immediate identification of these bodies as belonging to its original context? I wonder if those bodies that were never excluded from its original context, were ever perceived individual in their entirety. And if the exercise consists of inserting, virtually, those same bodies in other different contexts? Does your image or message captured changes?

Formalized it, yet, another exercise:

How we'll apprehend any context without the bodies?

Will be the hostage of the support elements that constitute it?

Leaving these issues, and exemplifying them using image manipulation, a reflection is proposed on the problems in question, with the aim of showing the power of mutation of a body when altered its context. In the extreme, and a route that swells the interrogations, detecting a mined territory analysis of guesswork that may interfere with historical lines assembled and with the intelligibility of objects and cultural and artistic time concerned.

Keywords: Body, image, context. 


\section{O PROBLEMA}

Quantas vezes paramos para observar uma imagem inserida neste ou naquele contexto?

Quanto tempo demora cada uma dessas nossas paragens? E o que é que observamos, na realidade?

A imagem? O contexto? Tudo ao mesmo tempo?

E o que é que fica na nossa memória? Do que é que nos lembramos a seguir? Do todo? Da imagem? Deste ou daquele pormenor?

Para além da "Criação de Adão", quem consegue lembrar-se com exactidão desta ou daquela imagem do tecto da Capela Sistina de Miguel Ângelo?

Para além do homem barbado, quem consegue lembrar-se com exactidão desta ou daquela imagem que pertence ao todo da Janela do Capítulo?

Quantas vezes os corpos que constituem uma imagem, ou estão presentes num determinado contexto são totalmente ignorados enquanto individualidade?

Inserido num determinado contexto, o corpo adquire um significado e uma imagem que não é mais do que o resultado do somatório dos inputes dados por esse mesmo contexto.

Karl Popper escreveu que, "O mito do contexto pode definir-se numa frase, como a que se segue: A existência de uma discussão racional e produtiva é impossivel, a menos que os participantes partilhem um contexto comum de pressupostos básicos ou, pelo menos, tenham acordado em semelhante contexto em vista da discussão." (POPPER 2009, 69).

Até que ponto os corpos expostos num qualquer museu ou espaço e fora do seu contexto original nos transmitem as mesmas mensagens?

Até que ponto o contexto per si determina e conduz o observador a uma leitura pré determinada?

Até que ponto não é absolutamente necessário retirar o contexto para poder existir uma análise/discussão crítica, racional e produtiva?

\section{OS CORPOS IN-SITU}

O exercício que aqui se propõe é uma reflexão sobre o que poderá acontecer se observamos imagens fora do seu contexto original.

Se tomarmos a fachada ocidental da nave manuelina do Convento de Cristo como exemplo para análise, concluímos que tal como se se tratasse de uma tapeçaria, a escultura nesta fachada adquire o caracter de elemento decorativo de conjunto. Não tem valor nem identidade individual. Atendendo à especificidade do exemplo escolhido, que se inscreve num universo

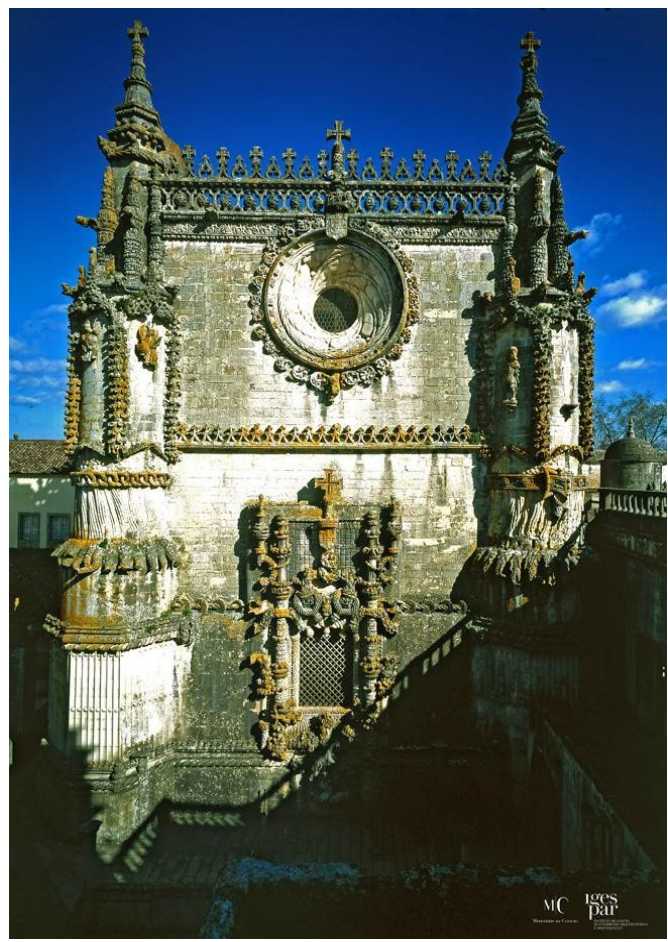

Fig.1 - Fachada Ocidental da Nave Manuelina.

simbólico utilizado na construção de uma mensagem de propaganda régia de carácter messiânico, estes corpos "decorativos" são, também eles, componentes deste discurso simbólico. É neste contexto que se identifica a fachada ocidental da nave manuelina como uma ponte iconográfica entre a Ordem de Cristo com a sua figura fundacional (Jesus, metaforicamente 
representado pelas molduras de árvore seca que em cima voltam a florescer, conferindo àquela o estatuto de Árvore da Vida, pois representa no ápice uma Cruz de Cristo) e as origens divinas da realeza manuelina, que era simultaneamente o governador da Ordem e ao mesmo tempo imperador, consubstanciando em si o poder sobre as esferas do terreal e celestial, governando os homens por imposição e escolha providencial de Deus. (PEREIRA 2009, 68).

Neste contexto, os corpos que constituem esta ponte iconográfica são identificados com a imagem de:

Jessé denderóforo (o velho transportando aos ombros a árvore das profecias), no corpo homem barbado;

O poder espiritual e o poder temporal, nos corpos dos anjos e os arautos de armas; O crente que, segundo Isaías, têm asas como a águia, corre sem se cansar, marcha sem desfalecer (Isaías 40:31). No corpo do homem águia que remata inferiormente o óculo da fachada.

In-situ, nenhum destes corpos tem leitura individual. Eles são reféns de um contexto que os aprisiona. Porque não há corpo! não há matéria! não há fragmento!

Existe, sim, a imposição de uma leitura interpretativa da mensagem de conjunto, inerente a esta imagem una.

Não se questiona a validade e o rigor desta leitura, já sobejamente difundida e comentada.

Questiona-se, sim, se esta leitura esgota a análise crítica, possível, a estes corpos.

\section{OS CORPOS EX-SITU O $1^{\circ}$ EXERCÍCIO}

Quando expurgarmos estes corpos do seu contexto, estas esculturas revelam a sua identidade própria, não contaminada pelo contexto da sua origem.

Assim, descontextualizando e aproximando estes corpos, uma leitura totalmente inovadora surge.

De repente, é perceptível que estamos perante imagens de nobres cavaleiros, trajados a rigor e ostentando elmos, escudos e caduceu, pormenorizadamente trabalhados.

São corpos de feição moderna, no tratamento da proporção, no trabalho do movimento dos corpos, nos panejamentos e na caracterização da expressão facial. A excelência da caracterização dos trajes envergados, caracteriza-os no contexto temporal da época. Contudo, a iconografia do nobre-militar, assumida pela primeira vez em Portugal por D. João I, parece ser uma temática exclusiva da escultura tumulária. Por princípio, reis e nobres faziam-se representar como cavaleiros nos seus leitos de morte (SILVA, 2009).

A rápida observação destes corpos sem o seu contexto sugere, desde já, inúmeras propostas de investigação, que vão desde a identificação das personagens que estas esculturas representam (através do pormenor das características físicas,

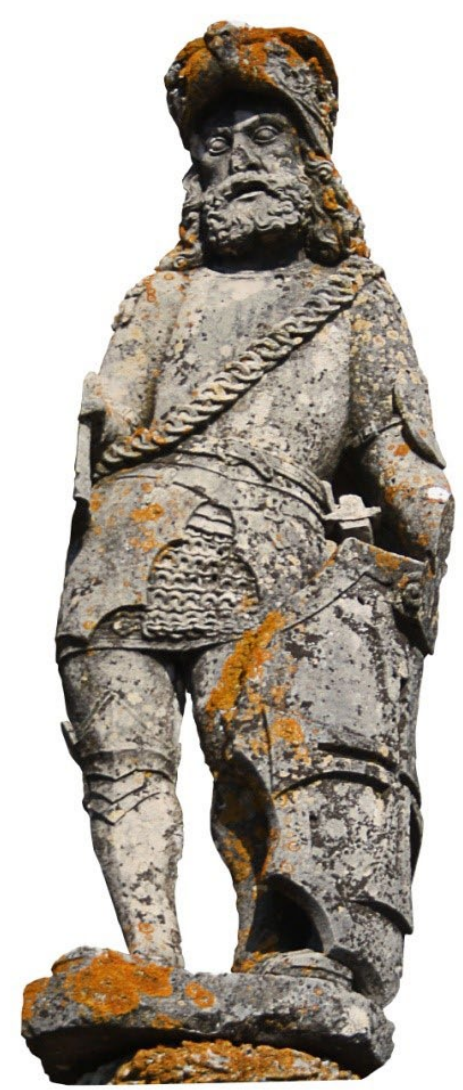

Fig.2 - Escultura existente no botaréu Sul. 
das vestes e dos símbolos militares que envergam); à autoria destas obras; ao lugar destas peças na história da escultura portuguesa; à história do traje militar; à história da heráldica; à concordância, ou não, com a leitura destes corpos in-situ; entre tantas outras.

A descontextualização dos corpos dos anjos revelou, também, feição moderna no tratamento da proporção, no do movimento dos corpos, nos panejamentos e na caracterização da expressão facial. Os seus corpos estão suspensos, simulando levitar, e os seus rostos são enérgicos e altivos.

Se pensarmos no caso do anjo custódio de Santa Cruz, que se posiciona de forma hierática e segura o escudo com a esfera armilar junto aos pés (CRAVEIRO, 2012), ou mesmo nos pertencentes à Charola, constatamos que estas representações contrariam a normal representação destes anjos.

Todo o tratamento plástico é de excelente qualidade, não só nos pequenos detalhes, como a execução das penas, o ondulado do cabelo e o movimento dos tecidos; como no tratamento de superfícies, como o desenho dos escudos.

Situação equivalente às estátuas dos cavaleiros.

A reflecção feita para as esculturas do botaréu Sul verifica-se, também, para estes corpos, sugerindo, desde logo, inúmeras propostas de leitura/investigação, que vão desde a caracterização destes anjos custódios (através da iconografia específica do Anjo e da heráldica régia, do pormenor das vestes e do movimento corporal); à autoria destas obras; ao lugar destas peças na história da escultura portuguesa; ao significado da utilização da figura do Anjo Custódio e do Anjo da Anunciação no discurso simbólico régio; à história da heráldica; à concordância, ou não, com a leitura destes corpos in-situ; entre tantas outras.

A descontextualização de figuras de menor dimensão, como o homem águia, põe em evidência uma incessante pormenorização na execução dos detalhes, até agora totalmente ignorada.

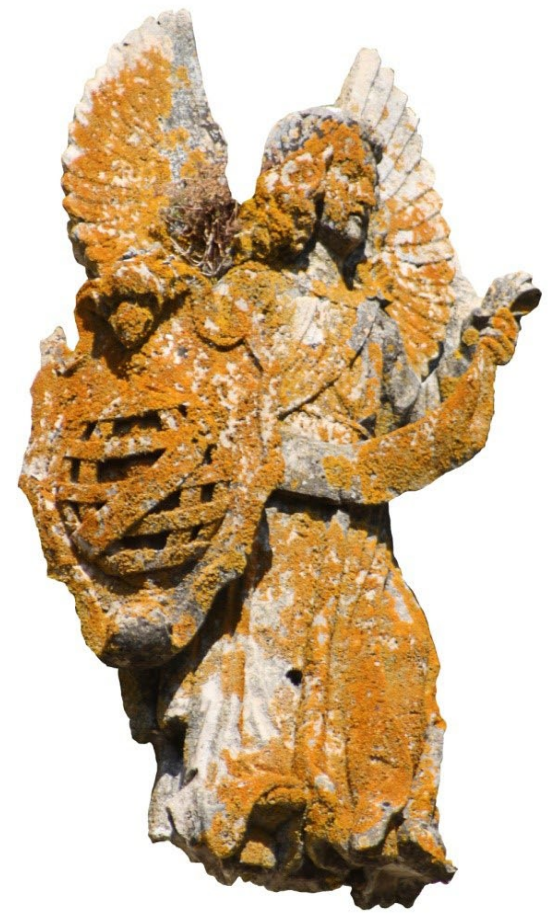

Fig.3 - Anjo Custódio existente no botaréu Norte.

Também aqui surgem novas leituras interpretativas, e novas análises se impõe.

Por último, a descontaminação do homem barbado da incontornável Janela do Capítulo, revela-nos a cabeça e dois braços de um homem de meia-idade, trajado de forma incaracterística, com um acentuado estrabismo e um pequeno chapéu colocado no topo da cabeça sobre uma cabeleira que cobre as orelhas.

Devido à ausência de um corpo completo, estes fragmentos corporais, sem o contexto, revelam uma fragilidade quase insustentável.

Mas será que os pormenores de caracterização, como o estrabismo, o chapéu com a pequena rosa na frente, os cabelos e barba, o tipo de mangas e punhos não nos permitiram formular outras leituras que contraponham a proposta de representação de Jessé? Ou do lendário marinheiro das caravelas?

Este corpo, libertado do seu contexto, impõe uma abordagem crítica à 
historiografia actual, abrindo caminho para novas correntes de investigação.
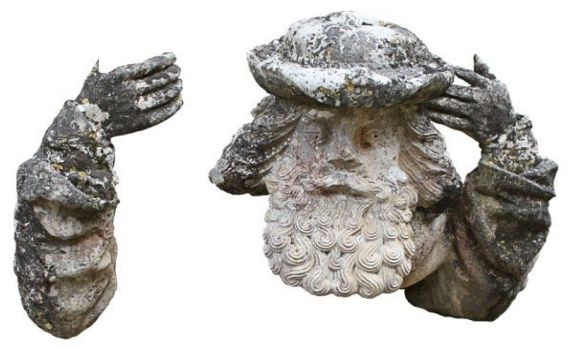

Fig.4 - O homem barbado da Janela do Capítulo.

\section{O $2^{\circ}$ EXERCÍCIO}

E agora que resgatámos a identidade a cada um dos corpos presentes, façamos o exercício de os inserir num outro contexto distinto, por exemplo no Museu do Louvre, e ensaiemos uma nova imagem para estes.

A integração e valorização do corpo, enquanto individualidade, é notória e imediata. Passam para o universo do Museu

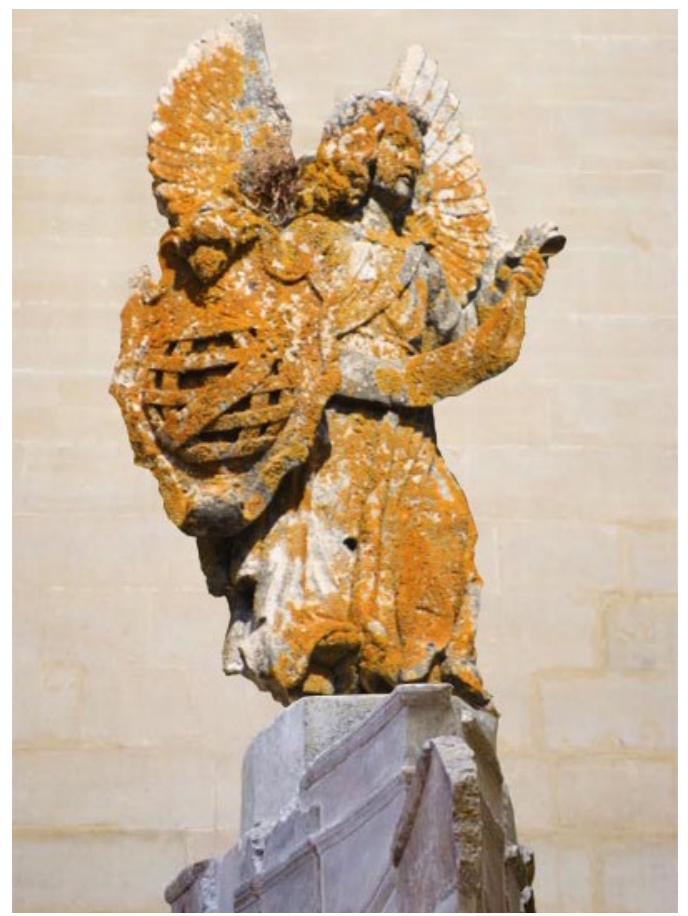

Fig.5 - Anjo Custódio no contexto expositivo da Victória de Samothrace.
Imaginário de André Malraux. Transcendem a sua escala, a sua nacionalidade, o seu espaço físico e temporal.

Revelam-se, unicamente, como corpos produzidos pela cultura Europeia/Ocidental

\section{O $3^{\circ}$ EXERCÍCIO}

Se no exercício anterior vimos que a introdução em contextos expositivos não altera a leitura da individualidade dos corpos, muito pelo contrário valorizou-a e criou uma nova imagem centrada em si, o exercício que se segue demonstra a possibilidade de subversão da identidade de um corpo quando inserido num novo contexto com identidade própria.

O homem barbado, estrábico, trajado de forma incaracterística e usando um chapéu de dimensões ridículas podia ser, inserido noutro contexto, o rosto desconhecido do primeiro presidente dos Estados Unidos George Washington.

Neste novo contexto, a imagem de Jessé distancia-se cada vez mais deste rosto barbado. O rosto que, juntamente com dois braços, outrora ostentava uma fragilidade quase insustentável, ganha nesta imagem uma leitura de segurança e poder.

O contexto contamina e determina a leitura da imagem.

\section{O $4^{\circ}$ E ÚLTIMO EXERCÍCIO}

E o contexto? Será a sua imagem alterada se retirarmos os corpos que a constituem?

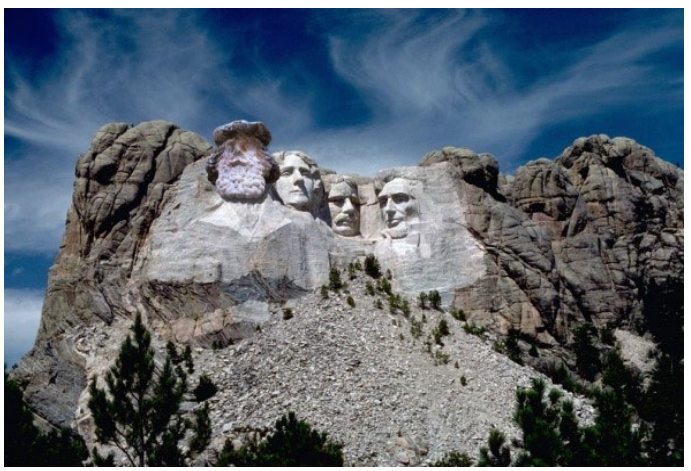

Fig.6 - O homem barbado no Mount Rushmore. 
Efectuamos o exercício de simular a retirada dos corpos da fachada.

O resultado revelou que a fachada sem os corpos mantém a sua leitura de imagem una, isto é, o contexto não se altera.

Efectuámos, ainda, o exercício de inserir outros corpos na fachada.

O resultado revelou que a fachada com outros corpos mantém a sua leitura de imagem una, isto é, o contexto também não se altera.

\section{TENTANDO FORMULAR UMA CONCLUSÃO}

O contexto determina e contamina a leitura e apreensão da imagem e dos corpos que a constituem.

O contexto raramente se altera pela supressão ou alteração dos corpos que o constituem.

A observação do pormenor vai de encontro ao primeiro diálogo entre o artista e a obra abrindo, assim, um novo caminho de investigação ao encontro da identidade individual do corpo.

A procura e o verdadeiro conhecimento de um qualquer corpo e o encontro com a sua real essência, conseguir-se-á apenas e só através da análise crítica desse mesmo corpo in e ex-situ e do confronto das análises aí obtidas.

\section{Bibliografia}

Alves, A. M. (1985). Iconografia do Poder Real no período manuelino, Lisboa, Imprensa Nacional - Casa da Moeda.

Craveiro, M.L. (2012). O Anjo Moderno, Universidade de Coimbra, CEAUCP.

Figueira, L. S. (2001). Técnicas de construção na arquitectura manuelina, Tese de doutoramento em história da arte na Faculdade de Letras da Universidade de Coimbra.

Leite, S. (2005). A Arte do Manuelino como percurso simbólico, Caleidoscópio - Edição e Artes Gráficas, S.A.

Malraux, A. (2001). O Museu Imaginário, Coleç. Arte e Comunicação, Edições 70.
Pereira, P. (1990). A obra silvestre e a esfera do Rei, Universidade de Coimbra.

Pereira, P. (2003). De Áurea Aetate, O Coro do Convento de Cristo de Tomar e a Simbólica Manuelina, Coleç. Monumentos / Monografias, Instituto Português do Património arquitectónico.

Pereira, P. (2009). Convento de Cristo, Instituto de Gestão do Património Arquitectónico e Arqueológico e Scala Publishers.

Popper, K. (2009). O Mito do Contexto. Em defesa da Ciência e da Racionalidade. Biblioteca de Filosofia, Lisboa, Edições 70.

Silva, J.C.V., Ramôa, J. (2009), A Escultura Tumular do Século XV em Portugal: Novos retratos sociais para um novo tempo, In: Colóquio Internacional de História de Arte - A Escultura em Portugal. Da Idade Média ao início da Idade Contemporânea: História e Património. Ed. Fundação as Casas de Fronteira e Alorna. 